\title{
Diagnostic Accuracy of Mammographic and Sonographic Findings in the Differentiation of Palpable Breast Masses taking Histopathology as a Gold Standard
}

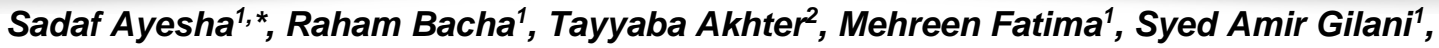 \\ Syed Yousaf Farooq ${ }^{1}$, Muhammad Yousaf', Muhammad Uzair', Mahjabeen Liaqat', Maimoona Rasool' \\ 1 University Institute of Radiological Sciences and Medical Imaging Technology, Faculty of Allied Health \\ Sciences University of Lahore, Pakistan. \\ 2 Radiology Department of Fatima Memorial Hospital.
}

\begin{abstract}
Authors' Contributions
1,2 Conception \& Study design, Drafting of

Manuscript, Critical Review.

3, 4 Data Collection \& Processing, Data

Analysis and/or Interpretation.

5,6 Data Analysis and/or Interpretation, Critical Review.

7, 8 Data Collection \& Processing, Drafting of Manuscript.

9, 10 Drafting of Manuscript, Critical Review.

\section{Article info}

Received: February 23, 2021

Accepted: April 11, 2021

Funding Source: Nil

Conflict of Interest: Nil

Cite this article: Ayesha S, Bacha R, Akhter T, Fatima M, Gilani SA, Farooq SY, Yousaf M, Uzair M, Liaqat M, Rasool M. Diagnostic Accuracy of Mammographic and Sonographic Findings in the Differentiation of Palpable Breast Masses taking Histopathology as a Gold Standard. RADS J Pharm Pharm Sci. 2021; 9(1):18-24
\end{abstract}

*Address of Correspondence Author: sadaf.ayesha59@yahoo.com

\begin{abstract}
A B S T R A C T
Background: The Presence of palpable breast mass may be an indication of breast cancer. Early and accurate diagnosis for the breast masses is important for therapeutic purpose.

Purpose: To assess the diagnostic accuracy of mammographic and sonographic findings in the differentiation of palpable breast masses taking histopathology as a gold standard.

Materials and Methods: 134 females were involved in the study. Sonographic and mammographic findings of palpable breast masses were obtained with the help of which diagnostic accuracy of ultrasound and mammography was calculated while taking histopathology as a gold standard.

Results: Mean age in 134 females was found to be $44.2 \pm 4.7$ years. Sn, Sp, PPV, NPV, disease prevalence and accuracy of ultrasound in diagnosis of palpable breast lumps were $99.09 \%, 79.17 \%, 95.61 \%, 95.00 \%, 82.09 \%$ and $95.52 \%$ respectively. Sn, Sp, PPV, NPV and accuracy of mammography in diagnosis of palpable breast lumps were $95.45 \%, 62.50 \%, 92.11 \%, 75.00 \%$ and $89.55 \%$ while disease prevalence was same as that of ultrasound i.e. $82.09 \%$ respectively.
\end{abstract}

Conclusion: Ultrasound showed higher diagnostic accuracy in the evaluation of palpable breast masses than mammography while taking histopathology as a gold standard. It is noteworthy in differentiating breast masses.

Keywords: Palpable Breast masses, ultrasound, mammography, histopathology.

\section{INTRODUCTION}

Breast is a gland consisting of various structures that are affected by hormones leading to the formation of different types of masses and lesions, in which $90 \%$ of the clinical presentation are related to benign masses [1]. Breast pain is by and large of two sorts: a repetitive coming and going discomfort, which is generally diffuse, on both sides, and is normally connected with feminine cycle, and a noncyclical pain, which is typically one-sided and limited. At the point when patients present with breast soreness, the doctors for the most part play out an intensive history and an actual assessment to assess for any basic masses [2]. A lump in the breast is a matter of great concern and can affect the life expectancy of the 
affected individual. Breast cancer is the commonest cancer in females and is the $2^{\text {nd }}$ leading cause of expiry in Asia [3]. In USA, each year almost 31\% new cancers cases of breast cancer are diagnosed in females [4]. [5]. In 2012, approximately 1.7 million new cases of breast malignant growth were analyzed around the world [6]. A breast mass that is palpable is described as a presiding mass if it is three dimensional, discernible from neighboring tissues, and asymmetrical in comparison with other side of breast [7]. The clinical distinction of a cancerous mass from a benign one is challenging; the medical as well as possible legal consequences of missing a palpable carcinoma are high [8]. There are different classes of breast lesions relying upon danger of advancement of malignancy. Breast infection and non-proliferative breast abnormality don't build the danger of disease whereas proliferative breast illness presents mellow and moderate danger separately [9]. Early distinguishing tools like mammography can readily identify area, structure, and size of breast abnormalities that can aid in diminishing morbidity and mortality due to breast malignancy essentially [10] [11].

While palpable breast masses appear to be very frequent and usually benign, they must be evaluated thoroughly and diagnosed quickly to rule out malignancy. For an accurate diagnosis of breast masses, an extensive clinical examination, imaging, and sampling of tissue are required. Mammography is used to diagnose occult malignancy in older women and can detect malignant breast masses; however, its sensitivity is lower in women under the age of forty. Ultrasound is a powerful tool for detecting cystic masses and guiding biopsy procedures. [12]. Early clinical recognition of breast cancer with the help of screening will lead to early diagnosis and minimizing the mortality rate. On mammography, the diagnosis of breast cancer has been observed to differ greatly. On the other hand, breast Ultrasonography has attained worldwide acceptance as a diagnostic method for evaluating breast cancer [13]. It is presently recognized to be a precious aid in breast imaging and a preferred imaging modality for identification as well as differentiation of breast masses [14].

A palpable mass that is not detected by both mammography and ultrasonography firmly requires biopsy histology [15]. Albeit, open careful biopsy is the 'best quality level' for analysis of discernible breast lumps, lately two kinds of insignificantly intrusive breast biopsy methods, center needle biopsy and fine needle aspiration biopsy (FNAB), have gotten set up for the symptomatic assessment of substantial breast masses [16]. FNAC of the breast has two primary objectives; to affirm radiological and clinically amiable sores consequently maintaining a strategic distance from pointless medical procedure, and to affirm radiological and clinically dangerous determinations in this way empowering conclusive therapy arranging in such manner, breast cytology has been demonstrated to be profoundly sensitive and precise [17].[18]. Currently, FNAC is renowned for its unmistakable potential benefits of being delicate, explicit, catalyst, effective, and secure, and has become a most important instrument in the analysis of significant breast masses. The approach is more agreeable for the patient and pathologist since no local or general sedation is used [19]. Most of the females visiting the hospitals having complain of palpable breast lump or a doubtful screening mammogram are diagnosed with a benign breast abnormality [20]. The specific spot of these demonstrative apparatuses in the evaluation of breast structure irregularity would rely upon the ability and accessibility of these tools in a clinical arrangement and furthermore on the age factor of the females just as on the clinicians' level of doubt of nature of the lesion. [21].

\section{MATERIALS AND METHODS}

A cross sectional analytical study with sample size 134 was performed in the radiology department of a hospital. The duration of study was nine months. All the patients were registered in this study after signing the informed consent form. Convenient sampling technique was used. All the females of 18 to 50 years of age with palpable breast masses were included in the study whereas pregnant females, lactating females and already diagnosed cases were excluded. Mammomat 1000, siemens was used for mammography and Toshiba Voluson with linear probe was used for ultrasonography. During mammography the patient was in standing position facing mammography machine. Cranio-caudal and medio-lateral oblique views of the breasts were obtained. Compression was applied with the help of compression paddle.

During ultrasound patient was lying on the couch in supine position, with hands below the neck. A linear 
Diagnostic Accuracy of Mammographic and Sonographic Findings in the Differentiation of Palpable Breast Masses taking Histopathology as a Gold Standard

7-12 MHz probe was used. After applying gel to the whole breast, scanning was done in circumferential way. First in the inner circle and then the outer circle. After this starting from 12 'O clock position, in a clock wise manner scanning was done radially. At the end nipple was scanned. Axillary region was scanned for enlarged lymph nodes. On ultrasound, features like echogenicity of mass, margins, lymph-nodes involved or not were used to calculate diagnostic accuracy of ultrasound. On mammography, features like radiodensity, margins and surrounding architectural distortion were used to calculate diagnostic accuracy of mammography.

\section{RESULTS}

The total number of patients included in current study was 134 and the calculated mean age was 44.2 $\pm S D 4.7$ ( $\min 27-\max 50$ ) years as shown in Table 1.

Out of 134 cases, 109 were found malignant on both ultrasound and histopathology whereas, 5 cases were diagnosed as malignant on ultrasound but benign on histopathology. 1 lesion was diagnosed as benign on ultrasound but malignant on histopathology and 19 lesions were diagnosed as benign on both ultrasound and histopathology (Table 2).

The sensitivity, specificity, positive predictive value, negative predictive value, disease prevalence and accuracy of ultrasound in diagnosis of palpable breast lumps while taking histopathology as gold standard was found to be $99.09 \%, 79.17 \%, 95.61 \%, 95.00 \%$, $89.02 \%$ and $95.52 \%$ respectively (Table 3 ).

Out of 134 cases, 105 were diagnosed as malignant on both mammography and histopathology whereas, 9 lesions were diagnosed as malignant on mammography but benign on histopathology. 5 lumps were diagnosed as benign on mammography but malignant on histopathology and 15 lesions were diagnosed as benign on both mammography and histopathology (Table 4).

The sensitivity, specificity, positive predictive value, negative predictive value, disease prevalence and accuracy of mammography in diagnosis of palpable breast lumps while taking histopathology as a gold standard were $95.45 \%, 62.50 \%, 92.11 \%, 75.00 \%$, $82.09 \%$ and $89.55 \%$ respectively as shown in (Table 5).

Table 1. Descriptive Statistics of the Age of the Patients.

\begin{tabular}{|c|c|c|c|c|c|c|}
\hline \multicolumn{7}{|c|}{ Descriptive Statistics } \\
\hline & N & Range & Minimum & Maximum & Mean & Std. Deviation \\
\hline Age & 134 & 23.00 & 27.00 & 50.00 & 44.2164 & 4.72294 \\
\hline
\end{tabular}

Table 2. Comparison Between Ultrasound and Histopathology Results.

\begin{tabular}{|c|c|c|c|c|}
\hline \multicolumn{2}{|c|}{} & \multicolumn{2}{c|}{ Histopathology results } & \multirow{2}{*}{ Total } \\
\hline \multicolumn{2}{|c|}{} & Malignant & Benign & \\
\hline \multirow{2}{*}{ US results } & Malignant & 109 & 5 & 114 \\
\cline { 2 - 5 } & Benign & 1 & 19 & 20 \\
\hline \multicolumn{2}{|c|}{ Total } & 110 & 24 & 134 \\
\hline
\end{tabular}

Table 3. Sensitivity and Specificity of Ultrasonography While Taking Histopathology as Gold Standard.

\begin{tabular}{|c|c|c|}
\hline Statistic & Value & $\mathbf{9 5 \%} \mathbf{C l}$ \\
\hline Sensitivity & $99.09 \%$ & $95.04 \%$ to $99.98 \%$ \\
\hline Specificity & $79.17 \%$ & $57.85 \%$ to $92.87 \%$ \\
\hline Positive Likelihood Ratio & 4.76 & 2.18 to 10.38 \\
\hline Negative Likelihood Ratio & 0.01 & 0.00 to 0.08 \\
\hline Disease prevalence $\left(^{*}\right)$ & $82.09 \%$ & $90.90 \%$ to $97.94 \%$ \\
\hline Positive Predictive Value $\left(^{*}\right)$ & $95.61 \%$ & $72.76 \%$ to $99.27 \%$ \\
\hline Negative Predictive Value $\left(^{*}\right)$ & $95.00 \%$ & $90.51 \%$ to $98.34 \%$ \\
\hline Accuracy $\left({ }^{*}\right)$ & $95.52 \%$ & \\
\hline
\end{tabular}


Diagnostic Accuracy of Mammographic and Sonographic Findings in the Differentiation of Palpable Breast Masses taking Histopathology as a Gold Standard

Table 4. Comparison Between Mammography and Histopathology Results.

\begin{tabular}{|c|c|c|c|c|}
\hline \multicolumn{2}{|c|}{} & \multicolumn{2}{c|}{ Histopathology results } & \multirow{2}{*}{ Total } \\
\hline \multirow{2}{*}{ Mammography results } & Malignant & Benign & \\
\cline { 2 - 4 } & Malignant & 105 & 9 & 114 \\
\cline { 2 - 4 } & Benign & 5 & 15 & 20 \\
\hline \multicolumn{2}{|c|}{ Total } & 110 & 24 & 134 \\
\hline
\end{tabular}

Table 5. Sensitivity and Specificity of Mammography While Taking Histopathology as Gold Standard.

\begin{tabular}{|c|c|c|}
\hline Statistic & Value & $\mathbf{9 5 \%} \mathbf{C l}$ \\
\hline Sensitivity & $95.45 \%$ & $89.71 \%$ to $98.51 \%$ \\
\hline Specificity & $62.50 \%$ & $40.59 \%$ to $81.20 \%$ \\
\hline Positive Likelihood Ratio & 2.55 & 1.52 to 4.27 \\
\hline Negative Likelihood Ratio & 0.07 & 0.03 to 0.18 \\
\hline Disease prevalence $\left(^{*}\right)$ & $82.09 \%$ & \\
\hline Positive Predictive Value $\left(^{*}\right)$ & $92.11 \%$ & $87.42 \%$ to $95.14 \%$ \\
\hline Negative Predictive Value $\left(^{*}\right)$ & $75.00 \%$ & $54.68 \%$ to $88.18 \%$ \\
\hline Accuracy $\left(^{*}\right)$ & $89.55 \%$ & $83.09 \%$ to $94.17 \%$ \\
\hline
\end{tabular}

\section{DISCUSSION}

The Presence of palpable breast mass may be an indication of breast cancer. Early and accurate diagnosis for the breast masses is important for therapeutic purpose. Current study was designed to assess the diagnostic accuracy of mammographic and sonographic findings in the differentiation of palpable breast masses taking histopathology as gold standard. The triple assessment, which involves a physical examination, mammography, and percutaneous biopsy, is the standard management for palpable breast lesions. Mammography has radiations related bio-effects and biopsy is an invasive procedure but ultrasound is non-invasive and free of radiations related bio-effects. With the improvement in ultrasound modalities, it is now possible to differentiate between malignant and benign breast lesions. The gold standard for the differentiation of benign and malignant breast mass is histopathology.

In this research, the diagnostic precision of mammographic and sonographic findings in the distinction of palpable breast masses was evaluated. Data was collected based on age, gender, and breast masses in married and unmarried women, without the distinction of benign and malignant breast masses.
134 females were studied, with 131 (97.8\%) married women and 3 unmarried women (2.2\%).

According to a study carried by Donnelly, $\mathrm{J}$ et al, $58.09 \%$ of these women were under the age of 30 , $31.12 \%$ were between the ages of 31 and 50 , and $10.78 \%$ were over the age of $50.70 .95 \%$ were married, while $29.04 \%$ were single. A clinically palpable lump in the breast was found in nearly $64.31 \%$ of the patients, and $35.68 \%$ had discomfort and other symptoms [22]. Patel et al. conducted a similar analysis, finding that $5.7 \%$ of the 200 patients were between the ages of 21 and 29, with pain being the most common mode of presentation. According to another analysis, the age and size of the lesion had a substantial relationship with the occurrence of malignancy, but the length of the lump had no such relationship [23]. In our study out of total number of 134 cases, $6(4.5 \%)$ cases belong to age group 25-35 years, $76(56.7 \%)$ cases belong to age group 36-45 years whereas $52(38.8 \%)$ belong to age group $46-55$ years.

The axillary nodes were palpable in various experiments, with varying outcomes. While axillary palpation has low sensitivity and specificity, it is frequently used to determine whether an invasive node biopsy or an axillary lymph node dissection should be conducted. The different studies show variable results the axillary nodes were palpable. Study was conducted by Cutuli et al who found the 
involvement of axillary lymph node, they concluded that upper and lower outer quadrants constituted the highest percentage of axillary lymph node involvement $(50 / 74,68 \%)$, next to it was the central area (nipple and areola complex) (14/74, 19\%) and the least incidence was encountered in inner quadrant lesions (10/74, 13\%)[24]. In current study result, lymph nodes were involved in 89 (66.6\%) cases whereas lymph nodes were not involved in 45 (33.6\%) cases.

Another study was conducted by Morris KT et al has stated that Triple test that is physical examination, radiography and pathology have diagnostic accuracy of $100 \%$. They have observed that out of 50 patients 33 were benign lesions. Out of that 13 were benign solid and 20 were cystic, 16 cases were fibro adenoma [25]. In current study result, Benign on ultrasound were $20(14.9 \%)$ and the cases diagnosed as malignant were 114 (85.1\%). On mammography palpable breast masses of 115 patients (85.8\%) were presented with irregular margins whereas palpable breast masses of remaining 18 patients (14.2\%) were presented with regular margins. Benign on mammography were $20(14.9 \%)$ and the cases diagnosed as malignant were $114(85.1 \%)$. In out of total number of 134 cases, 24(17.9\%) were diagnosed as Benign on Histopathology whereas $110(82.1 \%)$ were diagnosed as malignant on Histopathology. A study conducted by Fatima ST et al depicted ultrasound sensitivity $94.1 \%$, specificity $89.3 \%$, positive predictive value $77.4 \%$, negative predictive value $97.5 \%$ and diagnostic accuracy $90.7 \%$ [26]. Various studies have looked into the diagnostic accuracy of ultrasonography. According to a Gonzaga report, ultrasonography had a sensitivity and specificity of $57.1 \%$ and $62.8 \%$ in detecting breast cancer, respectively [27].

Ahmed ZT et al, 2020 conducted research on the diagnostic accuracy of Ultrasound and revealed that the mean age of females was 47.8 years and the sensitivity of Ultrasound was $94.1 \%$, specificity $89.3 \%$, Positive predictive value $77.4 \%$, Negative predictive Value $97.5 \%$ and diagnostic accuracy was $90.7 \%$ [28]. According to the findings of current study research, ultrasound has a sensitivity of $99.09 \%$ Specificity $79.17 \%$, Positive Predictive Value $95.61 \%$ Negative Predictive Value $95.00 \%$ and Accuracy 95.52\%.

Berg WA et al. performed another study in which they found that all benign lesions identified by ultrasonography (41 cases) were benign at histology. On ultrasonography, there were 62 lesions with malignant characteristics, with 52 true positives and 10 false positives. Thus, ultrasonography had an overall sensitivity of 100 percent and a specificity of 80.4 percent, with a positive predictive value of 83.9 and a negative predictive value of 100 , which are comparable to the results of Kolb et al, who found that ultrasonography's sensitivity, specificity, negative and positive predictive values, and accuracy were 75.3 percent, 96.8\%, and 100 percent, respectively [29]. Regarding mammography $14.8 \%$ of the 54 cases with malignant features on mammography were histologically benign. This study's overall sensitivity of mammography was 73.0 percent, with a precision of 80.0 percent, a positive predictive value of 85.2 , and a negative predictive value of 65.3. Various studies have indicated reduced sensitivity of mammography in younger females, even after amending breast density [30]. According to results of current study research the sensitivity of mammography is $95.45 \%$, Specificity $62.50 \%$, Positive Predictive Value $92.11 \%$, Negative Predictive Value $75.00 \%$ and Accuracy $89.55 \%$.

The diagnostic accuracy of mammography in the preoperative interrogation of breast lesions was determined by Berg WA et al, 2004. There were 177 malignant lesions in 121 cancerous breasts studied, with 89 (50\%) lumps palpable. The sensitivity of mammography reduced from 100 percent in fatty breasts to 45 percent in exceptionally dense breasts. For the diagnosis of Invasive Ductal Carcinoma, the US had a higher sensitivity than mammography [31]. In our study the sensitivity of ultrasound is also higher $99.09 \%$ than that of mammography which is $95.45 \%$.

\section{CONCLUSION}

Ultrasound showed higher diagnostic accuracy in the evaluation of palpable breast masses than mammography while taking histopathology as a gold standard. It is significant in differentiating breast masses therefore should be used for the evaluation of palpable breast masses.

\section{REFERENCES}

1. Jain SB, Jain I, Srivastava J, et al. A clinicopathological study of breast lumps in patients presenting in surgery OPD in a referral 
hospital in Madhya Pradesh, India. Int J Curr Microbiol App Sci 2015;4(8):919-923.

2. Leddy R, Irshad A, Zerwas E, et al. Role of breast ultrasound and mammography in evaluating patients presenting with focal breast pain in the absence of a palpable lump. Breast $\mathrm{J}$ 2013;19(6):582-589. 10.1111/tbj.12178.

3. Ghoncheh M, Momenimovahed Z, Salehiniya H. Epidemiology, incidence and mortality of breast cancer in Asia. Asian Pac $\mathrm{J}$ Cancer Prev 2016;17(sup3):47-52. dx.doi.org/10.7314.

4. Hooley RJ, Andrejeva L, Scoutt LM. Breast cancer screening and problem solving using mammography, ultrasound, and magnetic resonance imaging. Ultrasound Q J 2011;27(1):2347. 10.1097/RUQ.0b013e31820e15ac.

5. Chaudhary IA, Qureshi SK, Rasul S. Incidence of malignancy in females presenting with breast lumps in OPD: a study of 277 cases. Pak J Med Sci 2003;40(30):287-294.

6. NakuGhartey Jnr F, Anyanful A, Eliason S, et al. Pattern of breast cancer distribution in ghana: a survey to enhance early detection, diagnosis, and treatment. Int. J. Breast Cancer 2016;2016:1-9. 10.1155/2016/3645308.

7. Pruthi S. Detection and evaluation of a palpable breast mass. Mayo Clin Proc 2001;76(6):641-648. 10.4065/76.6.641.

8. Jahan $\mathrm{AB}$, Ahmed $\mathrm{MU}$, Begum $\mathrm{M}$, et al. Ultrasonographic Evaluation of Palpable Breast Mass and Correlation with Histopathology. Mymensingh Med J 2017;26(2):223-239. 10.1097/00006254-199303000-00014.

9. Velu AR, Srinivasamurthy BC, Rani J. Cytological evaluation of benign breast lesions with histopathological correlation. Indian J Pathol Oncol 2016;3(1):7-10.

10. Gurung G, Ghimire RK, Lohani B. Mammographic evaluation of palpable breast masses with pathological correlation: a tertiary care centre study in Nepal. JIOM Nepal 2010;32(2):2125.10.3126/jiom.v32i2.4940.

11. Likhar KS, Fatima A, Hazari RA, et al. Diagnostic role of FNAC in breast lesions. Indian J Res Rep Med Sci 2013;3:12-14.

12. Klein $\mathrm{S}$. Evaluation of palpable breast masses. Breast J 2005; 71(9):1731-8.

13. Tamaki $K$, Sasano $H$, Ishida $T$, et al. The correlation between ultrasonographic findings and pathologic features in breast disorders. Jpn J Clin Oncol 2010;40(10):905-912. 10.1093/jjco/hyq070.

14. Uematsu T. Ultrasonographic findings of missed breast cancer: pitfalls and pearls. Breast Cancer 2014;21(1):10-19.10.1007/s12282-013-0498-7.
15. Zhou Y. Ultrasound diagnosis of breast cancer. J. Med. Imaging Health Inf 2013;3:157-170. 10.1166/jmihi.2013.1157.

16. Ukah CO, Oluwasola OA. The clinical effectiveness of fine needle aspiration biopsy in patients with palpable breast lesions seen at the University College Hospital, Ibadan, Nigeria: A 10year retrospective study. J Cytol 2011;28(3):111113. 10.1159/000351306.

17. Bangaru H, Chandra AS, Gaiki VV. Clinical radiological and pathological assessment of benign breast lumps: our institutional experience. Int J Surg 2017;4(11):3627-3632. 10.18203/23492902.isj20174658.

18. Yusuf I, Atanda AT. Validity of fine needle aspiration cytology of the palpable breast lesions: A teaching hospital experience. Niger J Basic Clin Sci 2014;11(1):36-40. 10.4103/0331-8540.130170.

19. Begum F, Kumar PR. Diagnostic correlation of palpable breast masses by cytology and histopathology: A prospective study. Int Arch Integr Med 2018;5(11):44-49.

20. Keyzer-Dekker CM, Van Esch L, De Vries J, et al . An abnormal screening mammogram causes more anxiety than a palpable lump in benign breast disease. Breast Cancer Res Treat 2012;134(1):253-258. 10.1007/s10549-012-20255.

21. Takhellambam YS, Lourembam SS, Sapam OS, et al. Comparison of ultrasonography and fine needle aspiration cytology in the diagnosis of malignant breast lesions. Journal of clinical and diagnostic research: J Clin Diagn Res 2013;7(12):2847-2850.

10.7860/JCDR/2013/6493.3887.

22. Donnelly J. Breast lump detection: who is more accurate, patients or their GPs? Int $\mathrm{J}$ Clin Pract. 2010;64(4):439-441. 10.1111/j.17421241.2009.02257.x.

23. Gayatri L, Patil LS, Rajashri, D, Vijayanath V, Anitha MR. Benign Breast Disease at the Gynaecology Out Patient Clinic. Journal of Medical research and Practice, North America 2013;3:2127 .

24. Cutuli B, Velten M, Martin C. Assessment of axillary lymph node involvement in small breast cancer: analysis of 893 cases. Clinical breast cancer. 2001 Apr 1;2(1):59-65. 10.3816/CBC.2001.n.012.

25. Morris KT, Vetto JT, Petty JK, Lum SS, Schmidt WA, Toth-Fejel S, Pommier RF. A new score for the evaluation of palpable breast masses in women under age 40. Am J Surg. 2002;184(4):346-7. 10.1016/S00029610(02)00947-9. 
26. Fatima ST, Zahur Z, Jeilani A, Hussain SJA, Abbasi NZ, Khan AA, et al. Ultrasound-a useful complementary tool to mammography in assessment of symptomatic breast diseases. J Ayub Med Coll Abbottabad 2015;27(2):381-383.

27. Gonzaga MA. How accurate is ultrasound in evaluating palpable breast masses? Pan Afr Med J 2010;7(1). 10.4314/pamj.v7i1.69094.

28. Ahmed I, Nazir R, Chaudhary MY, Kundi S, Triple assessment of breast lump. J Coll Physicians Surg Pak. 2007;17(9):535- 8. 09.2007/jcpsp.535538.

29. Berg WA, Gutierrez L, NessAiver MS, et al. Diagnostic accuracy of mammography, clinical examination, US, and MR imaging in preoperative assessment of breast cancer. Radiology 2004;233(3):830-849. 10.1148/radiol.2333031484.

30. Kolb TM, Lichy J, Newhouse JH. Comparison of the performance of screening mammography, physical examination, and breast US and evaluation of factors that influence them: an analysis of 27,825 patient evaluations. Radiology 2002; 225(1):165-175. 10.1148/radiol.2251011667.

31. Berg WA, Gutierrez L, NessAiver MS, et al. Diagnostic accuracy of mammography, clinical examination, US, and MR imaging in preoperative assessment of breast cancer. Radiology 2004;233(3):830-849. 10.1148/radiol.2333031484. 